\title{
A Time to Fast, a Time to Feast: The Crosstalk between Metabolism and the Circadian Clock
}

\author{
Judit Kovac ${ }^{1,3}$, Jana Husse ${ }^{2,3}$, and Henrik Oster ${ }^{1, *}$
}

\begin{abstract}
The cyclic environmental conditions brought about by the $24 \mathrm{~h}$ rotation of the earth have allowed the evolution of endogenous circadian clocks that control the temporal alignment of behaviour and physiology, including the uptake and processing of nutrients. Both metabolic and circadian regulatory systems are built upon a complex feedback network connecting centres of the central nervous system and different peripheral tissues. Emerging evidence suggests that circadian clock function is closely linked to metabolic homeostasis and that rhythm disruption can contribute to the development of metabolic disease. At the same time, metabolic processes feed back into the circadian clock, affecting clock gene expression and timing of behaviour. In this review, we summarize the experimental evidence for this bimodal interaction, with a focus on the molecular mechanisms mediating this exchange, and outline the implications for clock-based and metabolic diseases.
\end{abstract}

\section{INTRODUCTION}

The adaptation to environmental changes brought about by the succession of day and night offers strong advantages for the efficient usage of natural resources and, hence, is a major evolutionary selection criterion (Pittendrigh, 1993). Not surprisingly, all but the simplest species living on Earth have evolved timekeeping mechanisms that enable them to predict and adapt to upcoming time-dependent events (Harmer et al., 2001). These internal clocks, termed circadian from Latin "circa diem" meaning "about a day", are a remarkable example of parallel evolution that emphasizes the importance of temporal resolution for living organisms. Circadian clocks anticipate daily events and adapt behaviour and physiology in an attempt to minimise energy expenditure and maximise the chance of survival.

Circadian regulation does not only serve the alignment of internal and external rhythms, but also provides a powerful means to achieve temporal compartmentalisation at both interand intracellular levels (Takahashi et al., 2008). According to the current model, mammalian circadian clocks are based on cellular oscillators built from a set of clock genes organised in interlocked transcriptional feedback loops. The transcription factors CLOCK (or, in some tissues, NPAS2) and BMAL1 (ARNTL) drive expression of two Cry and three Per genes, as well as hundreds of so called clock controlled genes (CCGs) via E-box mediated regulation. PER and CRY proteins negatively feed-back on CLOCK/BMAL1 activity, thereby generating a stable $24 \mathrm{hr}$ rhythm of transcriptional activity. Several accessory feedback loops - one of them involving the nuclear hormone receptors Rev-erb $\alpha$ (Nr1d1) and Ror $\alpha$ (Rora) - stabilise this rhythm and provide further means for in- and output to and from the molecular clock (Ko and Takahashi, 2006). The nature of CCGs varies between different tissues, providing a way to translate time information into physiologically meaningful signals (Duffield, 2003).

In mammals, a master circadian pacemaker is located in the hypothalamic suprachiasmatic nuclei (SCN). From the SCN peripheral clocks throughout the rest of the body are synchronised with each other and with external time. The synchronisation mechanisms of the circadian timing system have not yet been fully understood, but likely involve humoral, neuronal as well as indirect pathways such as the activity-mediated regulation of food intake and body temperature (Stratmann and Schibler, 2006). The major synchroniser (or Zeitgeber) of circadian rhythms is light. Light information reaches the SCN from visual and non-visual photoreceptors in the retina via the retinohypothalamic tract and results in the release of glutamate at SCN synapses (Foster and Hankins, 2007). Other Zeitgeber exist, but their signalling mechanisms are poorly studied. Some of them involve other brain nuclei and, most likely, other (peripheral) clocks. A striking example for this is the entrainment of peripheral oscillators by metabolic signals. Independently of the $\mathrm{SCN}$, the temporal restriction of food access can rapidly reset clock gene rhythms in many tissues such as the liver or the kidney (Damiola et al., 2000). Similarly, light has been shown to directly affect clocks in the adrenal cortex and the secretion of endocrine factors such as glucocorticoids from this gland (Ishida et al., 2005; Oster et al., 2006). It is likely that other time cues will affect different oscillators and provide additional input for the entrainment of the circadian timing system.

While food restriction uncouples SCN and peripheral clocks, there is also feedback from the periphery to the master pacemaker. This includes arousal-associated circuits and hormonesensitive brain areas such as the raphe or the arcuate nuclei

${ }^{1}$ Circadian Rhythms Group, Max Planck Institute of Biophysical Chemistry, 37077 Göttingen, Germany, ${ }^{2}$ Genes and Behaviour Department, Max Planck Institute of Biophysical Chemistry, 37077 Göttingen, Germany, ${ }^{3}$ These authors contributed equally to this work.

*Correspondence: henrik.oster@mpibpc.mpg.de 
that themselves project to the SCN (Buijs et al., 2006). A direct neuronal feedback, e.g. from the autonomic nervous system, is likely, but experimental evidence for this is still missing. The optimisation of energy expenditure is one of the main functions of circadian timekeeping (see above). Thus, efficient interactivity of the circadian and metabolic regulatory centres is crucial for optimal environmental adaptation. The molecular aspects of this cross-talk and its (patho-) physiological implications are summarised below.

\section{Circadian control of metabolism}

A major function of the circadian system is the regulation of the metabolic machinery in preparation for temporal variations in the abundance of nutrients. Not surprisingly, various humoral factors associated with metabolic control show diurnal rhythms of concentration such as glucose, fatty acids and triglycerides, but also glucocorticoids, insulin and catecholamines. By these means clock-regulated anticipation of external events optimizes physiological energy expenditure and, hence, increases general fitness (Bray and Young, 2007).

In humans, clock-related metabolic regulation is tightly linked to the regulation of sleep. The circadian clock regulates the sleep/ wake cycle by synchronising phases of sleepiness and arousal throughout the day. In addition, a homeostatic component of unknown anatomical origin regulates the "need for sleep" in response to prolonged wakefulness. Recent work suggests that both processes are not entirely separated and clock genes may affect both circadian and homeostatic circuits (Mistlberger, 2005). Changes in human lifestyle - most prominently observed during the last decades - have led to a striking decrease in average sleep duration in most industrial countries, correlated with a dramatic increase in the prevalence of metabolic disorders (Laposky et al., 2008). Acute sleep restriction in healthy subjects promotes increased appetite, reduced leptin secretion, elevated ghrelin levels, and increased glucose resistance (Spiegel et al., 1999; 2004). Likewise, shift workers show higher metabolic risk factors for the development of obesity, diabetes type II, metabolic syndrome and cardio-vascular disease (Bray and Young, 2007). All these attributes are under circadian control, indicating that metabolic phenotypes might be the consequence of a misalignment between circadian clocks and physiology (Shea et al., 2005). Genetic variations in human circadian clock genes have been associated with metabolic phenotypes. Haplotype analyses revealed that CLOCK gene polymorphisms are correlated with the development of metabolic syndrome, while certain $B M A L 1$ alleles are linked to type II diabetes and hypertension (Scott et al., 2007; Woon et al., 2007). These data propose that the transcription factors of the positive limb of the circadian clock may serve a protective role in the incidence of metabolic diseases.

Indications for a causal relationship between the circadian clock and metabolic regulation have been documented in circadian clock mutant mice (see Table 1). The dominant negative Clock mutant shows irregular locomotor activity and food intake behaviour. Clock animals develop obesity combined with increased levels of cholesterol, triglycerides, glucose and leptin, and a decrease in insulin secretion (Turek et al., 2005). Additionally, these mice absorb more lipids and carbohydrates than peptides via the intestine, most likely due to a lack of cyclic nutrient transport proteins (Pan and Hussain, 2009). Both, Clock mutant and Bmal1 deficient mice show impaired gluconeogenesis, glucose tolerance and insulin sensitivity (Rudic et al., 2004). In liver-specific Bmal1 deficient animals, defects in glucose balance are reflected by a loss of rhythmicity in the expression of genes important for glucose mobilisation such as glucose-6-phosphate translocase (S/c37a4), phosphoenolpyruvate carboxykinase 2 (Pck2), adenylate kinase 4 (Ak3/1) and glucose transporter 2 (SIc2a2) (Lamia et al., 2008). Similar to Clock mutant mice, Per2 deficient animals consume more food during their normal rest phase and develop obesity when fed on a high fat diet. Interestingly, this phenotype can be restored after intraperitoneal application of the melanocyte stimulating hormone $\alpha-\mathrm{MSH}$, involved in the regulation of appetite (Yang et al., 2009). Increased serum levels of very low density lipoproteins (VLDLs) and apolipoprotein C-III were found in mice lacking Rev-erbo (Raspe et al., 2002).

Peripheral clocks regulate cell and tissue physiology via the rhythmic activation of hundreds of CCGs in a tissue-specific manner (Fig. 1). Transcriptome studies in metabolically relevant peripheral tissues such as liver, adipocytes, pancreas and the heart highlight the importance of CCGs in the regulation of numerous metabolic processes (Laposky et al., 2008). It seems that many key regulatory elements of energy conversion pathways, such as glucose and lipid metabolism, mediate metabolic alignment with external time. In cultured adipocytes, BMAL1 controls adipogenesis via the induction of PPAR $\gamma, A P 2$ (FABP4), sterol regulatory element binding protein 1 (SREBP-1) and CCAAT/enhancer binding proteins ( $C / E B P S$ ) (Shimba et al., 2005). Defects in adipocyte differentiation were also seen in the absence of REV-ERB $\alpha$, an upstream regulator of Bmal1 transcription (Wang and Lazar, 2008). Additionally, REV-ERB $\alpha$ represses lipid metabolism by binding to an AGGTAC motif in the promoter region of ApoC-III (Raspe et al., 2002). In skeletal muscle, $\mathrm{ROR} \alpha$ regulates lipid homeostasis via direct activation of carnitine palmitoyltransferase 1 (CPT1), involved in fatty acid oxidation, and caveolin-3 (Lau et al., 2004). Rhythmic transcriptional activation by CLOCK/BMAL1 is a key regulator of lipid metabolic enzymes such as acyl-CoA oxidase $(A O X)$, 3hydroxy-3-methylglutaryl coenzyme A (HMG-CoA) synthase (Hmgcs1) and cellular retinol binding protein II (CRBP I) (Inoue et al., 2005).

Circadian regulation of metabolism is not limited to peripheral clocks, but at the same time involves functional modulation of metabolic control centres in the brain. Rhythmic clock gene expression has not only been shown in the SCN, but in many other brain regions. These include the forebrain nuclei proximal to the third ventricle that express orexigenic (NPY, AgRP) and anorexigenic (POMC, CART) neuropeptides, as well as the dorsomedial nucleus and orexin-expressing neurons of the lateral hypothalamus (Green et al., 2008). Both regions serve as relay sites to arousal- and feeding-regulatory centres in the brainstem and the basal hypothalamus, respectively. Clock gene function itself is essential for normal regulation of ghrelin, CART and orexin levels in the hypothalamus (Turek et al., 2005). Thus, the appropriate integration of central and peripheral metabolic circadian regulation seems essential for the finetuning of overall metabolic homeostasis.

A possible risk factor for cardiovascular disease is a circadian dysfunction of the heart, where CLOCK regulates myocardial oleate oxidation and oxygen consumption by activation of fatty acid transport protein 1 (S/c27a1) as well as of the a3 and b3 subunits of NADH hydrogenase (Ndufa3/b3) (Bray et al., 2008). Furthermore, metabolic processes unrelated to energy balance have been reported to be regulated by the circadian clock. BMAL1 target genes are involved in xenobiotic detoxification and the conversion of reactive oxygen species (ROS) which are prime candidates for causing age-related degenerative processes (Kondratov et al., 2006). PER2, on the other hand, has a protective role in the susceptibility to alcohol and the 
Table 1. Mediators of circadian clock metabolism interaction

\begin{tabular}{|c|c|c|c|c|}
\hline Factor & Tissue & Function & Targets & References \\
\hline \multicolumn{5}{|l|}{ Clock genes } \\
\hline Bmal1 & $\begin{array}{l}\text { Liver } \\
\text { Adipocytes }\end{array}$ & $\begin{array}{l}\text { Glucose mobilisation } \\
\text { Adipogenesis }\end{array}$ & $\begin{array}{l}\text { Slc37a4, Pck2, Ak3l1, Slc2a2 } \\
\text { Pparg2, Ap2, Srebp-1, C/EBPs }\end{array}$ & $\begin{array}{l}\text { Lamia et al. (2008) } \\
\text { Shimba et al. (2005) }\end{array}$ \\
\hline Clock & $\begin{array}{l}\text { Hypothalamus } \\
\text { Heart }\end{array}$ & $\begin{array}{l}\text { Appetite regulation } \\
\text { Oleate oxidation } \\
\text { Oxygen consumption }\end{array}$ & $\begin{array}{l}\text { Orexin, Ghrelin, Cart } \\
\text { Slc27a1 } \\
\text { Ndufa3/b3 }\end{array}$ & $\begin{array}{l}\text { Turek et al. (2005) } \\
\text { Bray et al. (2008) }\end{array}$ \\
\hline Per2 & Hypothalamus & Appetite regulation & $\alpha-\mathrm{MSH}$ & Yang et al. (2009) \\
\hline Rev-erb $\alpha$ & $\begin{array}{l}\text { Adipose tissue } \\
\text { Liver, serum, kidney }\end{array}$ & $\begin{array}{l}\text { Adipocyte differentiation } \\
\text { Triglyceride catabolism }\end{array}$ & $\begin{array}{l}\text { Pparg2 } \\
\text { APOC-III, VLDL triglycerides }\end{array}$ & $\begin{array}{l}\text { Wang and Lazar (2008) } \\
\text { Raspe et al. (2002) }\end{array}$ \\
\hline Ror $\alpha$ & Skeletal muscle & Fatty acid oxidation & Cpt1, Caveolin-3 & Lau et al. (2004) \\
\hline \multicolumn{5}{|c|}{ Metabolic sensors } \\
\hline Ppara & Liver & Lipid and energy metabolism & $\begin{array}{l}\text { Bmal1, } \\
\text { REV-ERB } \alpha\end{array}$ & $\begin{array}{l}\text { Canaple et al. (2006); } \\
\text { Gervois et al. (1999) }\end{array}$ \\
\hline Pparg & Adipose tissue & Adipocyte differentiation & REV-ERB $\alpha$ & Fontaine et al. (2003) \\
\hline$P g c-1 \alpha$ & Liver, skeletal muscle & $\begin{array}{l}\text { Gluconeogenesis and energy } \\
\text { metabolism }\end{array}$ & $B m a l 1, \mathrm{REV}-\mathrm{ERB} \alpha$ & Liu et al. (2007) \\
\hline $\begin{array}{l}\text { Sirt1, Nampt, } \\
\text { redox state }\end{array}$ & $\begin{array}{l}\text { Liver, mouse embryonic } \\
\text { fibroblasts }\end{array}$ & Cellular metabolism & $\begin{array}{l}\text { CLOCK (NPAS2) /BMAL1-mediated } \\
\text { transcription }\end{array}$ & $\begin{array}{l}\text { Nakahata et al. (2009); } \\
\text { Ramsey et al. (2009); } \\
\text { Rutter et al. (2001) }\end{array}$ \\
\hline CO, heme & Liver, HeLa cells & Oxidative metabolism & $\mathrm{REV}-\mathrm{ERB} \alpha, \mathrm{NPAS} 2$ & $\begin{array}{l}\text { Dioum et al. (2002); } \\
\text { Kaasik and Lee (2004); } \\
\text { Yin et al. (2007) }\end{array}$ \\
\hline
\end{tabular}

pathology of addiction (Spanagel et al., 2005).

\section{Metabolic control of circadian rhythms}

From the evidence summarised above it seems clear that major aspects of metabolism are under circadian control. However, communication between metabolism and the clock is not linear. Instead, there seems to be a bidirectional relationship where metabolic cues feedback on the regulation of circadian timing. Evidence from both human and animal studies as well as possible molecular mechanisms underlying such metabolic clock control are discussed in the following paragraphs.

The prevalence of obesity has been steadily increasing in the last decades, as has sleep curtailment (see above). Obese people tend to show changes in sleep architecture indicative of circadian clock disturbances (Resnick et al., 2003). For sleep disorders it is sometimes difficult to differentiate between altered sleep homeostasis and changes in the circadian control of sleep, but altered daily rhythms of humoral parameters in obese people strongly suggest an involvement of the circadian timing system. Obese people show severely blunted to absent rhythms in glucose tolerance over the course of the day (Van Cauter et al., 1997). Additionally, the diurnal secretion rhythms of ghrelin are severely altered in obese people compared with lean subjects (Yildiz et al., 2004). However, how the circadian deregulation of such parameters influences the development of the disease remains to be shown.

In rodents obesity can be either induced by high fat feeding (HFF) or by genetic manipulation resulting in an obese phenotype. Both approaches indicate that obesity impairs the regulation of circadian clocks. Feeding mice with a high fat chow lengthens the period of circadian locomotor activity and changes circadian

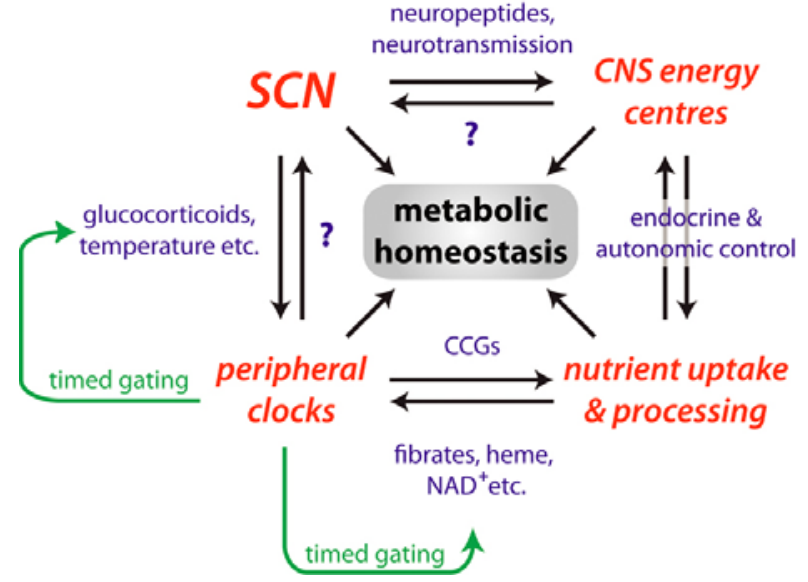

Fig. 1. Interaction of circadian and metabolic regulatory centres in the control of metabolic homeostasis. Central and peripheral circadian and metabolic centres (red) interact via humoral and neuronal factors (blue). Clock-controlled gating of the sensitivity of the target tissue for external stimuli (green) minimises the effect of noise and sporadic signalling events, promoting robust coupling between different oscillatory functions. For more details see text.

feeding patterns. Moreover, HFF affects clock gene rhythms in the liver as well as the circadian pattern of leptin, insulin and glucocorticoid levels in the blood (Kohsaka et al., 2007). Interestingly, not only feeding but also the complete withdrawal of food during fasting changes clock gene expression in peripheral tissues (Kawamoto et al., 2006). Obesity-inducing genetic mutations also lead to severe impairments of circadian rhythmicity. Mice defi- 
cient of the adipocyte satiety signal leptin (ob/ob) show a clear obese phenotype correlated with dampened locomotor activity rhythms and disrupted sleep architecture (Laposky et al., 2006). In another mouse model of diabetic obesity (KK-A mice) it was shown that the circadian clock is impaired at the molecular level. Clock gene rhythms in liver and white adipose tissue of $K K-A^{y}$ mice are severely attenuated (Ando et al., 2005). One study compared the effects of HFF and genetically induced obesity on clock gene expression and showed that clock gene rhythms in the CNS are equally disturbed in all obesity models (Kaneko et al., 2009). Taken together, human and mouse studies clearly suggest that obesity alters circadian clock regulation at the behavioural, physiological and molecular level.

The fact that feeding time can act as a Zeitgeber and change the phase of clock genes in peripheral organs, and most prominently in the liver, has long been known. Mice or rats that are subjected to a restricted feeding (RF) schedule, wherein food is only given for some hours during their normal sleeping time, show a complete uncoupling of peripheral clocks from the master pacemaker in the SCN: while clock gene expression in peripheral organs is entrained by the feeding schedule, the SCN retains its synchrony with the external light/dark cycle (Damiola et al., 2000). It remains unclear how the food-induced entrainment of peripheral clocks functions at the molecular level. Injection of the synthetic glucocorticoid dexamethasone can phase shift clock genes in the liver in a time-dependent manner (Balsalobre et al., 2000). Deletion of the glucocorticoid receptor in the liver, however, does not prevent entrainment of the liver clock after RF (Le Minh et al., 2001). Of course, nutrient components (carbohydrates, lipids and amino acids) themselves could affect the clock, and recent data suggest that metabolic cues might act on clock function through nuclear hormone receptors (NRs), some of which directly participate in the regulation of the circadian machinery. As sensors of dietary lipids, vitamins and lipophilic hormones, NRs are prime candidates for linking metabolism to the circadian clock. Indeed, about $50 \%$ of NRs show diurnal variations in expression and, hence, are themselves regulated by the circadian clock (Yang et al., 2006). Importantly, the two orphan nuclear receptors REV-ERB $\alpha$ (NR1D1) and ROR $\alpha$ (RORA) together represent one of the transcriptional feedback loops that underlie circadian regulation at the cellular level (Preitner et al., 2002; Sato et al., 2004). As $R e v$-erb $\alpha$ is required for adipogenesis and Ror $\alpha$ is important for lipid homeostasis, these two NRs might directly link metabolism to circadian clock function (Lau et al., 2004; Wang and Lazar, 2008). Peroxisome proliferator-activated receptor $\alpha$ (PPARA) is another important NR, a sensor for fatty acids and is involved in the regulation of energy metabolism (Lefebvre et al., 2006). Fibrates are known PPARA agonists that are used to treat symptoms of obesity and metabolic syndrome. Rev-erb $\alpha$ is a target of PPARA and fibrate treatment induces Rev-erb $\alpha$ expression via binding of PPARA to PPARA response elements in the Rev-erb $\alpha$ promoter (Gervois et al., 1999). Interestingly, PPARA is necessary for normal circadian clock gene expression in peripheral tissues such as the liver (Canaple et al., 2006). PPARA regulates Bmal1 expression via a PPAR response element in the Bmal1 promoter and is reciprocally regulated by CLOCK/BMAL1 (see Table 1). Ppara expression is phase shifted in response to a RF schedule and Ppara knockout mice show altered phase shifts in brown adipose tissue and heart after RF, implying that this NR might be one of the molecular mediators of food entrainment (Goh et al., 2007). Similar functions as for PPARA have also been proposed for its close relative PPARG (Fontaine et al., 2003). A known PPARinteracting factor is PGC-1 $\alpha$ (PPARGC1A), a transcriptional co- activator that plays a critical role in the maintenance of energy metabolism in a number of tissues. PGC-1 $\alpha$ is involved in thermogenesis in brown adipose tissue and in the regulation of gluconeogenesis in the liver (Lin et al., 2005). Besides metabolic abnormalities Pgc-1 $\alpha$ deficient mice display changes in important circadian parameters with a lengthened period of locomotor activity and perturbed clock gene expression in different tissues. PGC-1 $\alpha$ induces the clock gene Bmal1 via coactivation of RORs. Interestingly, and similar to Ppara deficient mice, food entrainment of the periphery is disrupted after a RF schedule in Pgc-1 $\alpha$ deficient mice (Liu et al., 2007), implicating that PGC-1 $\alpha$ might be involved in RF induced clock resetting.

Besides the involvement of NRs and NR-interacting factors in transmitting food signals to the molecular clock, clock genes themselves can be sensors for the metabolic state of the cell. Carbon monoxide (CO) inhibits the DNA binding of NPAS2 by favouring inactive BMAL1 homodimerization instead of active NPAS2/BMAL1 heterodimerization (Dioum et al., 2002). Along this line, NPAS2 and REV-ERB $\alpha$ have both been shown to act as heme sensors, where heme binding controls the DNA binding activity of these two core clock components (Kaasik and Lee, 2004; Yin et al., 2007). However, heme not only controls clock function, but the regulation of the rate limiting enzyme of heme biosynthesis, ALAS1, by the clock, reciprocally impacts on heme production itself (Kaasik and Lee, 2004). Additional evidence for clock genes being sensors of the cellular metabolic state comes from studies showing that the DNA binding activity of CLOCK/BMAL1 heterodimers is dependent on the redox state of the cell (Rutter et al., 2001). The molecular cascade underlying this phenomenon involves the rate limiting enzyme in the NAD synthesis, NAMPT, and the histone deacetylase SIRT1, a suppressor of CLOCK/BMAL1-mediated transcription (Nakahata et al., 2009; Ramsey et al., 2009). Interestingly - and similar to what was shown for heme - Nampt transcription itself is clock controlled, providing a mechanism for a gating of the sensitivity of the clock that allows a time-dependent response of peripheral circadian clocks to redox state signalling (Fig. 1).

\section{CONCLUSION}

In summary, it has become increasingly clear that circadian and metabolic regulation is tightly interlocked at both physiological and molecular levels (Fig. 1). The expression or enzymatic activity for key regulators of metabolic homeostasis show circadian rhythms, while metabolic sensors such as NRs and redox equivalents can directly feed-back on the transcriptional processes underlying the generation of circadian rhythmicity. These findings all point at a critical role for the circadian clock in the optimisation of energy expenditure and, thus, the increase of fitness under highly selective natural conditions. Such strict selective pressure does not exist under normal laboratory conditions. This might underlie the surprising fact that the evolutionary advantage of having a functional circadian timekeeping system has so far, at least in mammals, not been experimentally proven. Informative studies have been conducted in simpler species such as plants (Michael et al., 2003) and cyanobacteria. Mixing cultures of different strains of Synechococcus elongates shows that only those bacteria with an internal circadian period which closely matches the external light/dark cycle survive (Woelfle et al., 2004). Short life spans have been reported for Bmal1-deficient mice, but not for other clock mutants, indicating that this phenotype might represent a pleiotropic function of $\mathrm{Bmal1}$ besides its regulation of circadian timing (Kondratov et al., 2006).

Our modern lifestyle imposes new ways of pressure on the 
functionality of metabolism and clocks. Strictly timed (or even shift) work schedules and transcontinental travel together with the omnipresence of artificial lighting represent strong challenges for a primarily light-driven system such as the circadian clock. The consequence is what has been coined as social jetlag, a chronic misalignment of internal and external rhythms (Wittmann et al., 2006). Social jetlag - just like its air travel-associated brother might have strong implications for the functionality of metabolism, but also for immunity and cognitive performance.

The bilateral relationship of metabolic homeostasis and circadian clock function outlined above makes both systems vulnerable to factors impinging on the other. At the same time, it also offers new roads for the treatment of diseases associated with either of both processes. Time-scheduled and nutrientcontrolled food uptake can influence clock phase and stability and, thus, might help to alleviate disease symptoms associated with circadian misalignment such as sleep disruption, jetlag and various neuropsychiatric disorders (Oster and Foster, 2008). Likewise, resetting clock phase or strengthening internal synchronization, e.g. by timed light exposure or scheduled sleep/ wake times, might affect metabolic pathologies such as obesity, diabetes and night eating syndrome (Levi and Schibler, 2007). Given the increasing prevalence and fatality rates of obesityassociated disorders, tackling the circadian clock has the potential to become an important instrument in fighting obesity as a major plague of the industrialised world.

\section{ACKNOWLEDGMENTS}

We would like to thank Drs. Lars Geffers and Murat Yaylaoglu for critical comments on the manuscript. Work in the lab is supported by an Emmy Noether fellowship (H.O.) and a project grant (SFB654 Project B5) of the German Research Council (DFG).

\section{REFERENCES}

Ando, H., Yanagihara, H., Hayashi, Y., Obi, Y., Tsuruoka, S., Takamura, T., Kaneko, S., and Fujimura, A. (2005). Rhythmic messenger ribonucleic acid expression of clock genes and adipocytokines in mouse visceral adipose tissue. Endocrinology 146, 5631-5636.

Balsalobre, A., Brown, S.A., Marcacci, L., Tronche, F., Kellendonk, C., Reichardt, H.M., Schütz, G., and Schibler, U. (2000). Resetting of circadian time in peripheral tissues by glucocorticoid signaling. Science 289, 2344-2347.

Bray, M.S., and Young, M.E. (2007). Circadian rhythms in the development of obesity: potential role for the circadian clock within the adipocyte. Obes. Rev. 8, 169-181.

Bray, M.S., Shaw, C.A., Moore, M.W.S., Garcia, R.A.P., Zanquetta, M.M., Durgan, D.J., Jeong, W.J., Tsai, J.-Y., Bugger, H., Zhang, D., et al. (2008). Disruption of the circadian clock within the cardiomyocyte influences myocardial contractile function, metabolism, and gene expression. Am. J. Physiol. Heart Circ. Physiol. 294, H1036-1047.

Buijs, R.M., Scheer, F.A., Kreier, F., Yi, C., Bos, N., Goncharuk, V.D., and Kalsbeek, A. (2006). Organization of circadian functions: interaction with the body. Prog. Brain Res. 153, 341-360.

Canaple, L., Rambaud, J., Dkhissi-Benyahya, O., Rayet, B., Tan, N.S., Michalik, L., Delaunay, F., Wahli, W., and Laudet, V. (2006). Reciprocal regulation of brain and muscle Arnt-like protein 1 and peroxisome proliferator-activated receptor alpha defines a novel positive feedback loop in the rodent liver circadian clock. Mol. Endocrinol. 20, 1715-1727.

Damiola, F., Le Minh, N., Preitner, N., Kornmann, B., Fleury-Olela, F., and Schibler, U. (2000). Restricted feeding uncouples circadian oscillators in peripheral tissues from the central pacemaker in the suprachiasmatic nucleus. Genes Dev. 14, 29502961.

Dioum, E.M., Rutter, J., Tuckerman, J.R., Gonzalez, G., GillesGonzalez, M.A., and McKnight, S.L. (2002). NPAS2: a gas- responsive transcription factor. Science 298, 2385-2387.

Duffield, G.E. (2003). DNA microarray analyses of circadian timing: the genomic basis of biological time. J. Neuroendocrinol. 15, 991-1002.

Fontaine, C., Dubois, G., Duguay, Y., Helledie, T., Vu-Dac, N., Gervois, P., Soncin, F., Mandrup, S., Fruchart, J.C., FruchartNajib, J., et al. (2003). The orphan nuclear receptor RevErbalpha is a peroxisome proliferator-activated receptor (PPAR) gamma target gene and promotes PPARgamma-induced adipocyte differentiation. J. Biol. Chem. 278, 37672-37680.

Foster, R.G., and Hankins, M.W. (2007). Circadian vision. Curr. Biol. 17, R746-751.

Gervois, P., Chopin-Delannoy, S., Fadel, A., Dubois, G., Kosykh, V., Fruchart, J.C., Najib, J., Laudet, V., and Staels, B. (1999). Fibrates increase human REV-ERBalpha expression in liver via a novel peroxisome proliferator-activated receptor response element. Mol. Endocrinol. 13, 400-409.

Goh, B.C., Wu, X., Evans, A.E., Johnson, M.L., Hill, M.R., and Gimble, J.M. (2007). Food entrainment of circadian gene expression altered in PPARalpha-/- brown fat and heart. Biochem. Biophys. Res. Commun. 360, 828-833.

Green, C.B., Takahashi, J.S., and Bass, J. (2008). The meter of metabolism. Cell 134, 728-742.

Harmer, S.L., Panda, S., and Kay, S.A. (2001). Molecular bases of circadian rhythms. Annu. Rev. Cell Dev. Biol. 17, 215-253.

Inoue, I., Shinoda, Y., Ikeda, M., Hayashi, K., Kanazawa, K., Nomura, M., Matsunaga, T., Xu, H., Kawai, S., Awata, T., et al. (2005). CLOCK/BMAL1 is involved in lipid metabolism via transactivation of the peroxisome proliferator-activated receptor (PPAR) response element. J. Atheroscler. Thromb. 12, 169-174

Ishida, A., Mutoh, T., Ueyama, T., Bando, H., Masubuchi, S., Nakahara, D., Tsujimoto, G., and Okamura, H. (2005). Light activates the adrenal gland: timing of gene expression and glucocorticoid release. Cell Metab. 2, 297-307.

Kaasik, K., and Lee, C.C. (2004). Reciprocal regulation of haem biosynthesis and the circadian clock in mammals. Nature 430 467-471.

Kaneko, K., Yamada, T., Tsukita, S., Takahashi, K., Ishigaki, Y., Oka, Y., and Katagiri, H. (2009). Obesity alters circadian expressions of molecular clock genes in the brainstem. Brain Res. 1263, 58-68.

Kawamoto, T., Noshiro, M., Furukawa, M., Honda, K.K., Nakashima, A., Ueshima, T., Usui, E., Katsura, Y., Fujimoto, K., Honma, S., et al. (2006). Effects of fasting and re-feeding on the expression of Dec1, Per1, and other clock-related genes. J. Biochem. 140, 401-408.

Ko, C.H., and Takahashi, J.S. (2006). Molecular components of the mammalian circadian clock. Hum. Mol. Genet. 15, R271-277.

Kohsaka, A., Laposky, A.D., Ramsey, K.M., Estrada, C., Joshu, C., Kobayashi, Y., Turek, F.W., and Bass, J. (2007). High-fat diet disrupts behavioral and molecular circadian rhythms in mice. Cell Metab. 6, 414-421.

Kondratov, R.V., Kondratova, A.A., Gorbacheva, V.Y., Vykhovanets, O.V., and Antoch, M.P. (2006). Early aging and age-related pathologies in mice deficient in BMAL1, the core componentof the circadian clock. Genes Dev. 20,1868-1873.

Lamia, K.A., Storch, K.-F., and Weitz, C.J. (2008). Physiological significance of a peripheral tissue circadian clock. Proc. Natl. Acad. Sci. USA 105, 15172-15177.

Laposky, A.D., Shelton, J., Bass, J., Dugovic, C., Perrino, N., and Turek, F.W. (2006). Altered sleep regulation in leptin-deficient mice. Am. J. Physiol. Regul. Integr. Comp. Physiol. 290, R894903.

Laposky, A.D., Bass, J., Kohsaka, A., and Turek, F.W. (2008). Sleep and circadian rhythms: key components in the regulation of energy metabolism. FEBS Lett. 582, 142-151.

Lau, P., Nixon, S.J., Parton, R.G., and Muscat, G.E. (2004). RORalpha regulates the expression of genes involved in lipid homeostasis in skeletal muscle cells: caveolin-3 and CPT-1 are direct targets of ROR. J. Biol. Chem. 279, 36828-36840.

Le Minh, N., Damiola, F., Tronche, F., Schutz, G., and Schibler, U. (2001). Glucocorticoid hormones inhibit food-induced phaseshifting of peripheral circadian oscillators. EMBO J. 20, 71287136.

Lefebvre, P., Chinetti, G., Fruchart, J.C., and Staels, B. (2006). Sorting out the roles of PPAR alpha in energy metabolism and vascular homeostasis. J. Clin. Invest. 116, 571-580. 
Levi, F., and Schibler, U. (2007). Circadian rhythms: mechanisms and therapeutic implications. Annu. Rev. Pharmacol. Toxicol. 47, 593-628.

Lin, J., Handschin, C., and Spiegelman, B.M. (2005). Metabolic control through the PGC-1 family of transcription coactivators. Cell Metab. 1, 361-370.

Liu, C., Li, S., Liu, T., Borjigin, J., and Lin, J.D. (2007). Transcriptional coactivator PGC-1alpha integrates the mammalian clock and energy metabolism. Nature 447, 477-481.

Michael, T.P., Salome, P.A., Yu, H.J., Spencer, T.R., Sharp, E.L., McPeek, M.A., Alonso, J.M., Ecker, J.R., and McClung, C.R. (2003). Enhanced fitness conferred by naturally occurring variation in the circadian clock. Science 302, 1049-1053.

Mistlberger, R.E. (2005). Circadian regulation of sleep in mammals: Role of the suprachiasmatic nucleus. Brain Res. Rev. 49, 429454.

Nakahata, Y., Sahar, S., Astarita, G., Kaluzova, M., and SassoneCorsi, P. (2009). Circadian control of the NAD+ salvage pathway by CLOCK-SIRT1. Science 324, 654-657.

Oster, H., and Foster, R.G. (2008). The interaction of light and the circadian clock network - a new therapeutic approach for the treatment of neuropsychiatric disorders? In Progress in Circadian Rhythms Research, A.-L. Léglise, ed. (Hauppauge, NY: Nova Science Publishers), pp. 35-65.

Oster, H., Damerow, S., Kiessling, S., Jakubcakova, V., Abraham, D., Tian, J., Hoffmann, M.W., and Eichele, G. (2006). The circadian rhythm of glucocorticoids is regulated by a gating mechanism residing in the adrenal cortical clock. Cell Metab. 4, 163-173.

Pan, X., and Hussain, M.M. (2009). Clock is important for food and circadian regulation of macronutrient absorption in mice. J. Lipid Res. [Epub ahead of print]

Pittendrigh, C.S. (1993). Temporal organization: reflections of a Darwinian clock-watcher. Annu. Rev. Physiol. 55, 16-54.

Preitner, N., Damiola, F., Lopez-Molina, L., Zakany, J., Duboule, D., Albrecht, U., and Schibler, U. (2002). The orphan nuclear receptor REV-ERBalpha controls circadian transcription within the positive limb of the mammalian circadian oscillator. Cell 110, 251-260.

Ramsey, K.M., Yoshino, J., Brace, C.S., Abrassart, D., Kobayashi, Y., Marcheva, B., Hong, H.K., Chong, J.L., Buhr, E.D., Lee, C., et al. (2009). Circadian clock feedback cycle through NAMPTmediated NAD+ biosynthesis. Science 324, 651-654.

Raspe, E., Duez, H., Mansen, A., Fontaine, C., Fievet, C., Fruchart, J.-C., Vennstrom, B., and Staels, B. (2002). Identification of Reverb\{alpha\} as a physiological repressor of apoC-III gene transcription. J. Lipid Res. 43, 2172-2179.

Resnick, H.E., Redline, S., Shahar, E., Gilpin, A., Newman, A., Walter, R., Ewy, G.A., Howard, B.V., and Punjabi, N.M. (2003). Diabetes and sleep disturbances: findings from the Sleep Heart Health Study. Diabetes Care 26, 702-709.

Rudic, R.D., McNamara, P., Curtis, A.M., Boston, R.C., Panda, S., Hogenesch, J.B., and Fitzgerald, G.A. (2004). BMAL1 and CLOCK, two essential components of the circadian clock, are involved in glucose homeostasis. PLoS Biol. 2, e377.

Rutter, J., Reick, M., Wu, L.C., and McKnight, S.L. (2001). Regulation of clock and NPAS2 DNA binding by the redox state of NAD cofactors. Science 293, 510-514

Sato, T.K., Panda, S., Miraglia, L.J., Reyes, T.M., Rudic, R.D., McNamara, P., Naik, K.A., FitzGerald, G.A., Kay, S.A., and Hogenesch, J.B. (2004). A functional genomics strategy reveals Rora as a component of the mammalian circadian clock. Neuron 43, 527-537.

Scott, E.M., Carter, A.M., and Grant, P.J. (2007). Association between polymorphisms in the Clock gene, obesity and the metabolic syndrome in man. Int. J. Obes. 32, 658-662.
Shea, S.A., Hilton, M.F., Orlova, C., Ayers, R.T., and Mantzoros, C.S. (2005). Independent circadian and sleep/wake regulation of adipokines and glucose in humans. J. Clin. Endocrinol. Metab. 90, 2537-2544

Shimba, S., Ishii, N., Ohta, Y., Ohno, T., Watabe, Y., Hayashi, M., Wada, T., Aoyagi, T., and Tezuka, M. (2005). Brain and muscle Arnt-like protein-1 (BMAL1), a component of the molecular clock, regulates adipogenesis. Proc. Natl. Acad. Sci. USA 102, 1207112076.

Spanagel, R., Pendyala, G., Abarca, C., Zghoul, T., SanchisSegura, C., Magnone, M.C., Lascorz, J., Depner, M., Holzberg, D., Soyka, M., et al. (2005). The clock gene Per2 influences the glutamatergic system and modulates alcohol consumption. Nat Med. 11, 35-42.

Spiegel, K., Leproult, R., and Van Cauter, E. (1999). Impact of sleep debt on metabolic and endocrine function. Lancet 354 1435-1439.

Spiegel, K., Tasali, E., Penev, P., and Cauter, E.V. (2004). Brief communication: sleep curtailment in healthy young men is associated with decreased leptin levels, elevated ghrelin levels, and increased hunger and appetite. Ann. Intern. Med. 141, 846850.

Stratmann, M., and Schibler, U. (2006). Properties, entrainment, and physiological functions of Mammalian peripheral oscillators. J. Biol. Rhythms 21, 494-506.

Takahashi, J.S., Hong, H.K., Ko, C.H., and McDearmon, E.L. (2008). The genetics of mammalian circadian order and disorder: implications for physiology and disease. Nat. Rev. Genet. 9, 764775

Turek, F.W., Joshu, C., Kohsaka, A., Lin, E., Ivanova, G., McDearmon, E., Laposky, A., Losee-Olson, S., Easton, A., Jensen, D.R., et al. (2005). Obesity and metabolic syndrome in circadian Clock mutant mice. Science 308, 1043-1045.

Van Cauter, E., Polonsky, K.S., and Scheen, A.J. (1997). Roles of circadian rhythmicity and sleep in human glucose regulation. Endocr. Rev. 18, 716-738.

Wang, J., and Lazar, M.A. (2008). Bifunctional role of Rev-erbalpha in adipocyte differentiation. Mol. Cell. Biol. 28, 2213-2220.

Wittmann, M., Dinich, J., Merrow, M., and Roenneberg, T. (2006). Social jetlag: misalignment of biological and social time. Chronobiol. Int. 23, 497-509.

Woelfle, M.A., Ouyang, Y., Phanvijhitsiri, K., and Johnson, C.H. (2004). The adaptive value of circadian clocks: an experimental assessment in cyanobacteria. Curr. Biol. 14, 1481-1486.

Woon, P.Y., Kaisaki, P.J., Braganca, J., Bihoreau, M.-T., Levy, J.C., Farrall, M., and Gauguier, D. (2007). Aryl hydrocarbon receptor nuclear translocator-like (BMAL1) is associated with susceptibility to hypertension and type 2 diabetes. Proc. Natl. Acad. Sci. USA 104, 14412-14417.

Yang, X., Downes, M., Yu, R.T., Bookout, A.L., He, W., Straume, M., Mangelsdorf, D.J., and Evans, R.M. (2006). Nuclear receptor expression links the circadian clock to metabolism. Cell 126, 801-810.

Yang, S., Liu, A., Weidenhammer, A., Cooksey, R.C., McClain, D., Kim, M.K., Aguilera, G., Abel, E.D., and Chung, J.H. (2009). The role of mPer2 Clock gene in glucocorticoid and feeding rhythms. Endocrinology 150, 2153-2160.

Yildiz, B.O., Suchard, M.A., Wong, M.L., McCann, S.M., and Licinio, J. (2004). Alterations in the dynamics of circulating ghrelin adiponectin, and leptin in human obesity. Proc. Natl. Acad. Sci. USA 101, 10434-10439.

Yin, L., Wu, N., Curtin, J.C., Qatanani, M., Szwergold, N.R., Reid R.A., Waitt, G.M., Parks, D.J., Pearce, K.H., Wisely, G.B., et al. (2007). Rev-erbalpha, a heme sensor that coordinates metabolic and circadian pathways. Science 318, 1786-1789. 